LEADING ARTICLE

\title{
Microbes, immunoregulation, and the gut
}

\author{
G A W Rook, L R Brunet
}

Gut 2005;54:317-320. doi: 10.1136/gut.2004.053785

Two distinct, but rapidly converging, areas of research (the hygiene hypothesis and the study of probiotic/prebiotic effects) have emphasised the need to understand, and ultimately to manipulate, our physiological interactions with commensal flora, and with other transient but harmless organisms from the environment that affect immunoregulatory circuits. The story began with allergic disorders but now inflammatory bowel disease is increasingly involved.

See end of article for authors' affiliations

.....................

Correspondence to: Professor G Rook, Centre for Infectious Diseases and International Health, Windeyer Institute of Medical Sciences, Royal Free and University College Medical School, 46 Cleveland St, London WIT 4JF, UK; g.rook@ ucl.ac.uk

Received

10 September 2004

Accepted for publication

21 September 2004

\section{EARLY FORMULATIONS OF THE HYGIENE HYPOTHESIS}

The hygiene hypothesis was first proposed in the late 1980 s to explain the rise in allergic conditions (reviewed by Rook and colleagues ${ }^{1}$ ). The incidence of these disorders in the USA and Europe increased from the late 19th century, and appears to have doubled in some decades, particularly during the 1960s and 1970s. Epidemiological correlations with the modern way of life prompted the assumption that modern hygiene was reducing contact with pathogens that prime $\mathrm{T}$ helper $\mathrm{l}$ (Thl) responses. At that time it was believed that this would result in a compensatory increase in $\mathrm{T}$ helper 2 (Th2) activity that characterises allergic disorders. This concept, requiring Thl inducing infections to control Th2 mediated allergic conditions, arose because of the remarkable compartmentalisation of medical knowledge. Readers of this journal, aware of the simultaneous increase in several Thl mediated disorders such as Crohn's disease, type 1 diabetes, and multiple sclerosis, will be sceptical. Indeed, the incidences of allergic disorders (Th2) and of type 1 diabetes (Thl) correlate closely both within Europe and outside. $^{2}$

\section{IMMUNOREGULATORY DISORDERS}

The unifying hypothesis that can explain the simultaneous increase in autoimmunity and inflammatory bowel disease (IBD) (Thl mediated) and allergies (Th2 mediated) is that modern living conditions can lead to defective maturation of regulatory $\mathrm{T}$ cells $\left(\mathrm{T}_{\text {reg }}\right)$ and regulatory antigen presenting cells $\left(\mathrm{APC}_{\text {reg }}\right)$. Therefore, rather than Th1/Th2 balance, the crucial factor is likely to be the effector $\mathrm{T}$ cells $\left(\mathrm{T}_{\text {effector }}\right) / \mathrm{T}_{\text {reg }}$ balance. In the absence of optimal levels of immunoregulation, the individual may develop a Th1 or a Th2 mediated inflammatory disorder, depending on his/her own particular
Th1/Th2 bias, immunological history, and genetic background. The argument that a similar lack of $\mathrm{T}_{\text {reg }}$ activity could underlie the increases in such diverse disorders as allergies, IBD, and autoimmunity is given added weight by the observation that mice or humans who have genetic defects of the transcription factor Foxp3, which is required for some $T_{\text {reg }}$ functions, have a syndrome that includes components of all of these disease types. Thus diminished immunoregulation can lead to inappropriate immune responses to allergens, gut contents, or self (discussed by Rook and colleagues ${ }^{1}$ ).

\section{$T_{\text {REG }}$ DEFECTS IN CHRONIC INFLAMMATORY DISORDERS}

If this reinterpretation of the hygiene hypothesis is correct, the increase in human immunoregulatory disorders is at least partly attributable to defective $\mathrm{T}_{\text {reg }}$ activity. Evidence to confirm this hypothesis has come from studies of allergic disorders, ${ }^{3}$ multiple sclerosis, ${ }^{4}$ autoimmune polyglandular syndromes, ${ }^{5}$ and cow's milk intolerance. ${ }^{6}$ It is likely to be true for IBD too, though more difficult to prove. The intestine is always in a state of controlled inflammation, and T cells of the regulatory phenotype are abundant in the guts of patients with IBD. ${ }^{7}$ Nevertheless, data from animal models of IBD suggest that the problem is likely to be an immunoregulatory one, ${ }^{8}$ and there is evidence that there is defective induction of oral tolerance in IBD patients. ${ }^{9}$ Moreover, they have exaggerated responses to bowel flora ${ }^{10}$ which also appear to be the disease triggering antigens in animal models. ${ }^{8}$

\section{MICROBIAL EXPOSURE AND IMMUNOREGULATION}

How does this $\mathrm{T}_{\text {reg }}$ orientated concept relate to the original hygiene hypothesis, and why would microbial exposure affect maturation of regulatory pathways? To answer these questions we must first establish what we mean by hygiene.

One interpretation of the word "hygiene" in this context, mostly promoted by the media, assumes that the critical factor is domestic hygiene (bathing, soaps, detergents, antibacterial kitchen cutting boards, etc). However, a comprehensive recent report has shown that the development of these practices in the home does not correlate with the observed changes in the occurrence of immunoregulatory disorders. ${ }^{11}$

Abbreviations: IBD, inflammatory bowel disease; Th1, Th2, Thelper 1, 2; $T_{\text {effector, }}$ effector T cells, whether Th1 or Th2; $\mathrm{T}_{\text {reg, }}$ regulatory T cell; APC, APC reg, antigen presenting cell/regulatory antigen presenting cell; DC, dendritic cell; TLR, toll-like receptor; $\mathrm{KO}$, gene knockout; IL, interleukin; TGF- $\beta$, transforming growth factor $\beta$ 
A second view is that the critical change is the decreased frequency of infections due to pathogenic organisms. When the data available from the Centres for Disease Control and Prevention for the incidence of some infections are plotted against time, the graphs suggest that some of the decreases did occur during the critical period 1960-1985 when some chronic inflammatory disorders were doubling every decade. ${ }^{12}$ However, more detailed analysis of European data reveals that most of the changes in exposure to pathogens took place long before the crucial period. ${ }^{11}$ In addition, there is strong epidemiological evidence to suggest that certain pathogens, such as childhood viruses and respiratory infections, cause an increase rather than a decrease in the incidence of allergic disorders. ${ }^{13}$ Interestingly, despite the detrimental effect of infections, this study still identified protective effects of being sent to day care, keeping pets, and living on a farm. ${ }^{13}$ The latter has been a consistently robust observation, and the protective effect of exposing children to cowsheds is well documented. ${ }^{14}$ If childhood infections do not protect and home hygiene does not correlate, what might be the protective factors associated with pets, farms, and day care centres?

"Contact with "old friends" is greatly diminished in rich countries but increased on farms, in cowsheds, and through contact with pets"

The answer might lie in certain relatively harmless microorganisms (including helminths, saprophytic mycobacteria, and lactobacilli) that have been present throughout mammalian evolution. We have called this the "old friends" hypothesis. ${ }^{1}$ Contact with "old friends" is greatly diminished in rich countries but increased on farms, in cowsheds, and through contact with pets. A number of reports have provided evidence for this interpretation. Allergic disorders are less frequent in individuals with helminth infections, and atopic sensitisation increases after treatment of intestinal helminths. ${ }^{15}$ Similarly, there are less lactobacilli in the guts of children with allergies, ${ }^{16}$ and a preliminary clinical study suggests that high doses of lactobacilli may inhibit development of atopic eczema in genetically high risk children. ${ }^{17}$ Finally, the saprophytic mycobacterium $M$ vaccae, originally isolated, as its name suggests, from a cow shed, potently drives maturation of $\mathrm{T}_{\text {reg }}$ that will treat pre-existing allergy in a mouse model ${ }^{18}$ and has given encouraging results in clinical trials in allergic disorders. ${ }^{19} 20$

\section{THE MECHANISM BEHIND THE "OLD FRIENDS" HYPOTHESIS}

We suggest that because of our long evolutionary association with these organisms, they are recognised by the innate immune system as harmless or, in the case of some helminths, treated as "friends" because a response would merely lead to immunopathology (fig 1). Therefore, rather than priming aggressive immune responses, these organisms prime immunoregulation. ${ }^{1}$ They do it by inducing an unusual pattern of maturation of dendritic cells (DC) $)^{21}$ such that these retain the ability to drive $\mathrm{T}_{\text {reg }}$. This effect requires the innate immune system. Toll-like receptor 2 (TLR2) may be involved for helminths ${ }^{21}$ and TLR9 for lactobacilli.. ${ }^{23}$ It is interesting that polymorphisms of NOD2 (an intracellular receptor for bacterial peptidoglycan) are linked to increased susceptibility to both Crohn's disease ${ }^{24}$ and asthma. ${ }^{25}$ Thus an extension of the "old friends" mechanism suggests that in an environment that less actively primes $\mathrm{T}_{\text {reg }}$ activity, immunoregulatory disorders will occur first in those individuals whose innate immune systems are least efficient at driving $\mathrm{T}_{\text {reg. }}{ }^{26}$

\section{BYSTANDER AND SPECIFIC IMMUNOREGULATION}

The increased $\mathrm{DC}_{\text {reg }}$ and $\mathrm{T}_{\text {reg }}$ induced by "old friends" then lead to two immunoregulatory mechanisms mediated in part by release of interleukin (IL)-10 and transforming growth factor $\beta$ (TGF- $\beta)$. Firstly, continuing exposure to "old friends" will cause continuous background activation of $\mathrm{T}_{\text {reg }}$ specific for the "old friends" themselves, resulting in a constant background of bystander suppression.

\begin{abstract}
"Continuing exposure to "old friends" will cause continuous background activation of $\mathrm{T}_{\text {reg }}$ specific for the "old friends" themselves, resulting in a constant background of bystander suppression"
\end{abstract}

This mechanism has been elegantly demonstrated in a model of colitis. ${ }^{27}$ Secondly, $\mathrm{DC}_{\text {reg }}$ inevitably sample self, gut contents, and allergens and so induce $\mathrm{T}_{\text {reg }}$ specific for the target antigens of the three groups of chronic inflammatory disorder. These mechanisms may be aborted when there are legitimate "danger" signals. For example, $\mathrm{T}_{\text {reg }}$ function can be turned off by appropriate "danger signals" in vitro. ${ }^{28}$

\section{"OLD FRIENDS", THE GUT, AND PROBIOTICS}

"Old friends" provide a conceptual link between the increase in allergic disorders, which triggered the formulation of the hygiene hypothesis, and the simultaneous increase in IBD, as similar organisms may be involved. For example, Weinstock et al have reviewed evidence that diminished exposure to helminths is a critical factor in the increase in IBD. They also have encouraging clinical results using oral delivery of the ova of Trichuris suis, which transiently colonises the human intestine. ${ }^{29}$ Similarly, there have been several preliminary studies of the efficacy of bacterial probiotics, usually derived from lactobacillus strains, for inducing or maintaining remission in IBD (reviewed by Sartor ${ }^{30}$ ). This issue was discussed at a recent meeting of the International Scientific Association for Probiotics and Prebiotics (ISAPP; http:// www.isapp.net/).

\section{"We hypothesise that in the context of IBD, the property that matters most is the ability to drive $\mathrm{T}_{\text {reg }}$ "}

Some of the effects of probiotics are beginning to be understood at a molecular level and involve striking mechanisms, including competition for ecological niches within the gut, inhibition of signalling via nuclear factor $\kappa \mathrm{B}$, direct antimicrobial effects of secreted components, modulation of apoptosis, and activation of macrophages that take part in driving epithelial repair (partly reviewed by Ghosh and colleagues ${ }^{31}$ ). However, we hypothesise that in the context of IBD, the property that matters most is the ability to drive $\mathrm{T}_{\text {reg. }}$.

\section{PROBIOTICS AND T $\mathrm{REG}$}

There is evidence that some probiotics can induce $\mathrm{T}_{\text {reg. }}$. Orally administered Lactobacillus casei reduced skin inflammation due to contact sensitivity in animals sensitised to dinitrofluorobenzene. ${ }^{32}$ This finding cannot be attributed to the local gut specific effects of $L$ casei but rather appears to require CD4+ $\mathrm{T}$ cells and is likely to have been mediated by $\mathrm{T}_{\text {reg }}$. Moreover, some strains of lactobacillus mature DC so that they release little TNF- $\alpha$ or IL-12 but maintain their ability to release IL-10. This might facilitate induction of $\mathrm{T}_{\text {reg. }}{ }^{33}{ }^{34} \mathrm{In}$ IL-10 gene knockout (KO) mice, probiotics that attenuate the colitis to which these animals are susceptible downregulate Thl cytokines while maintaining TGF- $\beta .^{35}$ Both oral and subcutaneous administration promote this effect. ${ }^{36}$ This activity of lactobacilli via the subcutaneous route protects 


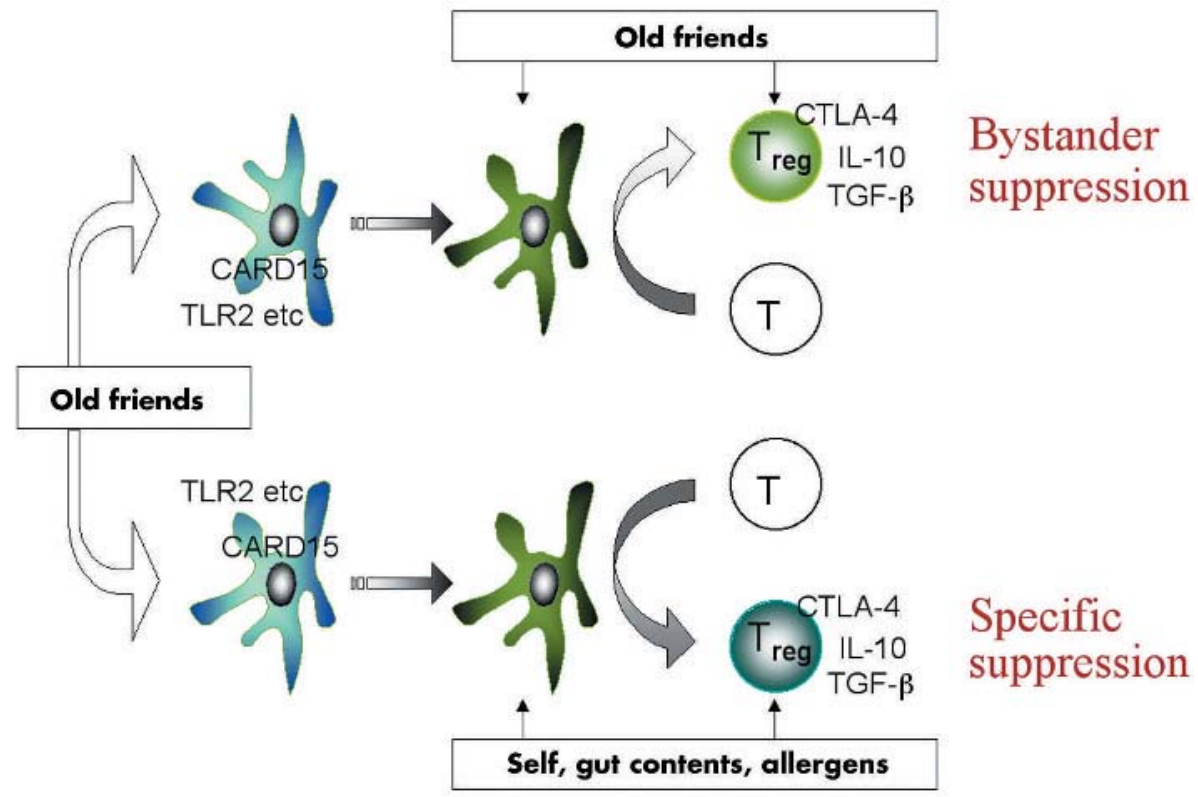

Figure 1 A diagram of the hypothesised modes of action of "old friends" and immunoregulatory probiotics. The "old friends", which have been present throughout mammalian evolutionary history, are recognised as harmless by the innate immune system and so cause antigen presenting cells (APC) to mature into regulatory APC $\left(A P C_{\text {reg }}\right)$ that drive regulatory $T$ cell $\left(T_{\text {reg }}\right)$. Some of these $T_{\text {reg }}$ will recognise the "old friends" themselves and so provide continuous background bystander regulation. However, APC reg will also process and present epitopes from self, allergens, and gut contents, and so drive specific immunoregulation. These mechanisms can be silenced in the presence of appropriate danger signals. In the absence of "old friends", both specific and bystander regulation will be defective. IL-10, interleukin 10; TGF- $\beta$, transforming growth factor $\beta$; TLR2, toll-like receptor 2 .

not only against colitis in IL-10 KO mice but also against collagen arthritis, a mainly Thl mediated model of autoimmunity. ${ }^{36}$

\section{"The gut may be the major site for $\mathrm{T}_{\text {reg }}$ induction even} when the probiotic is given subcutaneously"

The fact that probiotics work in models of colitis and arthritis, whether given orally or subcutaneously, is evidence that the important function in this context is not a gut specific one. Once generated, $\mathrm{T}_{\text {regs }}$ can travel to other tissues. It is interesting however that the gut may be the major site for $\mathrm{T}_{\text {reg }}$ induction even when the probiotic is given subcutaneously. Antigens containing bacterial polysaccharides $^{37} 38$ or whole organisms, ${ }^{39}$ even when given parenterally, may evoke a pattern of response, detected as IgA secreting cells in peripheral blood, that mimics the response to mucosal immunisation. It seems likely that this is due to cross reactivity with antigens already experienced by the gut associated lymphoid tissue. Moreover, induction of IgA in the gut is heavily dependent on TGF- $\beta$ which is also closely involved in the maturation of $\mathrm{T}_{\text {reg. }}{ }^{40}$

\section{CONCLUSIONS}

The "old friends" hypothesis has evolved into a concept similar to that which lies behind attempts to modulate disease by altering the bowel flora. The strong parallels point to the following conclusions. Firstly, we suggest that the strains (whether "old friends" or probiotics; whether bacteria or helminths) used for clinical trials in disorders of immunoregulation (allergies, IBD, autoimmunity) ought to be those which can be shown to drive $T_{\text {reg. Secondly, the }}$ particular organism used might need to be tailored to the individual patient. The "old friends" mechanism implies that, in rich countries, we live in an environment that does not efficiently prime $\mathrm{T}_{\text {reg }}$ activity. This might precipitate immunoregulatory disorders most frequently in those individuals whose innate immune systems have genetic polymorphisms that further reduce the efficiency of $\mathrm{T}_{\text {reg }}$ induction. ${ }^{26}$ Clearly, an immunotherapeutic that requires TLR2 to drive $\mathrm{T}_{\text {reg }}$ will not work in an individual in whom this receptor is nonfunctional.

Ultimately, the answer must lie in more rigorous proof that diminishing exposure to these $\mathrm{T}_{\text {reg }}$ inducing organisms is a factor in the increase in immunoregulatory disorders. If confirmed, we will be able to devise subtle changes to our lifestyles that reconstitute this exposure by the oral route.

\section{Authors' affiliations}

G A W Rook, L R Brunet, Centre for Infectious Diseases and International Health, Windeyer Institute of Medical Sciences, Royal Free and University College Medical School, London, UK

Conflict of interest: None declared.

\section{REFERENCES}

1 Rook GA, Adams V, Hunt J, et al. Mycobacteria and other environmental organisms as immunomodulators for immunoregulatory disorders. Springer Semin Immunopathol 2004;25:237-55.

2 Stene LC, Nafstad P. Relation between occurrence of type 1 diabetes and asthma. Lancet 2001;357:607.

3 Akdis M, Verhagen J, Taylor A, et al. Immune responses in healthy and allergic individuals are characterized by a fine balance between allergenspecific T regulatory 1 and T helper 2 cells. J Exp Med 2004; 199:1567-75.

4 Viglietta V, Baecher-Allan C, Weiner HL, et al. Loss of functional suppression by CD4+CD25+ regulatory T cells in patients with multiple sclerosis. $J$ Exp Med 2004; 199:971-9.

5 Kriegel MA, Lohmann T, Gabler C, et al. Defective suppressor function of human CD4+ CD25+ regulatory T cells in autoimmune polyglandular syndrome type II. J Exp Med 2004; 199:1285-91.

6 Karlsson MR, Rugtveit J, Brandtzaeg P. Allergen-responsive CD4+CD25+ regulatory $T$ cells in children who have outgrown cow's milk allergy. J Exp Med 2004; 199:1679-88.

7 Makita S, Kanai T, Oshima S, et al. CD4+CD25bright T cells in human intestinal lamina propria as regulatory cells. J Immunol 2004;173:31 19-30.

8 Powrie F, Read S, Mottet C, et al. Control of immune pathology by regulatory T cells. Novartis Found Symp 2003;252:92-8.

9 Kraus TA, Toy L, Chan L, et al. Failure to induce oral tolerance to a soluble protein in patients with inflammatory bowel disease. Gastroenterology 2004; 126:1771-8. 
10 Duchmann $\mathbf{R}$, Kaiser I, Hermann E, et al. Tolerance exists towards resident intestinal flora but is broken in active inflammatory bowel disease (IBD). Clin Exp Immunol 1995; 102:448-55

11 Stanwell-Smith R, Bloomfield S. The hygiene hypothesis and its implications for home hygiene. Milano: NextHealth Srl, 2004.

12 Bach JF. The effect of infections on susceptibility to autoimmune and allergic diseases. N Engl J Med 2002;347:91 1-20.

13 Benn CS, Melbye M, Wohlfahrt J, et al. Cohort study of sibling effect, infectious diseases, and risk of atopic dermatitis during first 18 months of life. BMJ 2004; 328:1223.

14 Riedler J, Braun-Fahrlander C, Eder W, et al. Exposure to farming in early life and development of asthma and allergy: a cross-sectional survey. Lancet 2001;358:1129-33

15 Yazdanbakhsh M, Matricardi PM. Parasites and the hygiene hypothesis: regulating the immune system? Clin Rev Allergy Immunol 2004;26:15-24.

16 Bjorksten B, Naaber P, Sepp E, et al. The intestinal microflora in allergic Estonian and Swedish 2-year-old children. Clin Exp Allergy 1999;29:342-6.

17 Kalliomaki M, Salminen S, Arvilommi H, et al. Probiotics in primary prevention of atopic disease: a randomised placebo-controlled trial. Lancet 2001;357:1076-9.

18 Zuany-Amorim C, Sawicka E, Manlius C, et al. Suppression of airway eosinophilia by killed Mycobacterium vaccae-induced allergen-specific regulatory T-cells. Nat Med 2002;8:625-9.

19 Arkwright PD, David TJ. Intradermal administration of a killed Mycobacterium vaccae suspension (SRL 172) is associated with improvement in atopic dermatitis in children with moderate-to-severe disease. J Allergy Clin Immunol 2001; 107:531-4.

20 Camporota L, Corkhill A, Long $\mathrm{H}$, et al. The effects of Mycobacterium vaccae on allergen-induced airway responses in atopic asthma. Eur Respir J 2003;21:287-93.

21 van der Kleij D, Latz E, Brouwers JF, et al. A novel host-parasite lipid cross talk. Schistosomal lyso-phosphatidylserine activates Toll-like receptor 2 and affects immune polarization. J Biol Chem 2002;277:48122-9.

22 Adams VC, Hunt J, Martinelli R, et al. Mycobacterium vaccae induces a population of pulmonary antigen presenting cells that have regulatory potential in allergic mice. Eur J Immunol 2004;34:631-8.

23 Rachmilewitz D, Katakura K, Karmeli F, et al. Toll-like receptor 9 signaling mediates the anti-inflammatory effects of probiotics in murine experimental colitis. Gastroenterology 2004; 126:520-8.

24 Ogura Y, Bonen DK, Inohara N, et al. A frameshift mutation in NOD2 associated with susceptibility to Crohn's disease. Nature 2001;411:603-6.

\section{EDITOR'S QUIZ: GI SNAPSHOT}

\section{A rare case of hypalbuminaemic oedema}

\section{Clinical presentation}

A 35 year old male patient presented massive anasarca, eyelid oedema, and dyspnoea. He also complained of mild diarrhoea and pain in the right calf. Further examination revealed the presence of ascites, bilateral pleural, as well as pericardial effusion. Serum electrophoresis revealed severe hypo- and dysproteinaemia with dramatically reduced albumin and an increased alpha-2 peak. Tenderness of the right calf was shown to be caused by multiple arterial embolisms on angiography. Due to pronounced acceleration of the erythrocyte sedimentation rate, increased acute phase reactants fibrinogen and ferritin, normal $\mathrm{C}$ reactive protein, and pronounced hypercholesterolaemia $(465 \mathrm{mg} / \mathrm{dl}$ ), nephrotic syndrome was first suspected but was ruled out (for example, by protein excretion scintigraphy). Stool $\alpha_{1}$ antitrypsin, elastase, and fat excretion were normal. The histology of the duodenal mucosa obtained by endoscopy is shown in fig 1 .

\section{Question}

What is the diagnosis? How should the condition be treated? See page 335 for answer

This case is submitted by:

M Merger, T Andus*, K Schlottmann, A Timmer, J Schölmerich, H Messmann†

Department of Internal Medicine I, University of Regensburg, Germany J Marienhagen

Department of Nuclear Medicine, University of Regensburg, Germany

P Rümmle

Department of Pathology, University of Regensburg, Germany
25 Kabesch M, Peters W, Carr D, et al. Association between polymorphisms in caspase recruitment domain containing protein 15 and allergy in two German populations. J Allergy Clin Immunol 2003;111:813-17.

26 Rook GA, Martinelli R, Brunet LR. Innate immune responses to mycobacteria and the downregulation of atopic responses. Curr Opin Allergy Clin Immunol 2003:3:337-42.

27 Groux H, O'Garra A, Bigler M, et al. A CD4+ subset inhibits antigen-specific T cell responses and prevents colitis. Nature 1997;389:737-42.

28 Pasare C, Medzhitov R. Toll pathway-dependent blockade of CD4+CD25+ T cell-mediated suppression by dendritic cells. Science 2003;299:1033-6.

29 Weinstock JV, Summers R, Elliott DE. Helminths and harmony. Gut 2004;53:7-9

30 Sartor RB. Therapeutic manipulation of the enteric microflora in inflammatory bowel diseases: antibiotics, probiotics, and prebiotics. Gastroenterology 2004:126:1620-33.

31 Ghosh S, van Heel D, Playford RJ. Probiotics in inflammatory bowel disease: is it all gut flora modulation? Gut 2004;53:620-2.

32 Chapat L, Chemin K, Dubois B, et al. Lactobacillus casei reduces CD8(+) T cellmediated skin inflammation. Eur J Immunol 2004:34:2520-8.

33 Christensen HR, Frokiaer H, Pestka JJ. Lactobacilli differentially modulate expression of cytokines and maturation surface markers in murine dendritic cells. J Immunol 2002;168:171-8.

34 Asseman C, Powrie F. Interleukin 10 is a growth factor for a population of regulatory T cells. Gut 1998:42:157-8.

35 McCarthy J, O'Mahony L, O'Callaghan L, et al. Double blind, placebo controlled trial of two probiotic strains in interleukin 10 knockout mice and mechanistic link with cytokine balance. Gut 2003;52:975-80.

36 Sheil B, McCarthy J, O'Mahony L, et al. Is the mucosal route of administration essential for probiotic function? Subcutaneous administration is associated with attenuation of murine colitis and arthritis. Gut 2004;53:694-700.

37 Tarkowski A, Lue C, Moldoveanu Z, et al. Immunization of humans with polysaccharide vaccines induces systemic, predominantly polymeric $\lg \mathrm{A} 2$ subclass antibody responses. J Immunol 1990;144:3770-8.

$38 \mathrm{Kehrl} \mathrm{JH}$, Fauci AS. Activation of human B lymphocytes after immunization with pneumococcal polysaccharides. J Clin Invest 1983;71:1032-40.

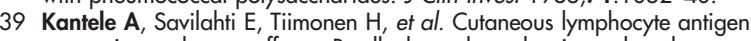
expression on human effector $B$ cells depends on the site and on the nature of antigen encounter. Eur J Immunol 2003:33:3275-83.

40 Fantini MC, Becker C, Monteleone G, et al. Cutting edge: TGF-beta induces a regulatory phenotype in CD4+CD25- T cells through Foxp3 induction and down-regulation of Smad7. J Immunol 2004;172:5149-53.

Current addresses: *Klinik für Allgemeine Innere Medizin, Gastroenterologie, Hepatologie und Onkologie, Prießnitzerweg 24, 70374 Stuttgart, Germany; †lll Medizinische Klinik, Klinikum Augsburg, 86009 Augsburg, Germany 